\title{
SELF-MEDICATION AMONG ADULT POPULATION IN SELANGOR, MALAYSIA
}

\author{
SUHANA JAWAHIR ${ }^{*}$, NOORIZAN ABD AZIZ² \\ 1 Institute for Health Systems Research, Ministry of Health Malaysia, No 55-1, 55-2, 55-3, 55-4, Setia Avenue, No. 2, Jalan Setia Prima $S$ \\ U13/S, Seksyen U13 Setia Alam, 40170 Shah Alam, Selangor, Malaysia, ${ }^{2}$ Faculty of Pharmacy, Universiti Teknologi MARA, Puncak Alam \\ Campus, Bandar Puncak Alam, 42300 Selangor, Malaysia \\ Email: suhana.j@moh.gov.my \\ Received: 02 Dec 2016 Revised and Accepted: 13 Apr 2017
}

\begin{abstract}
Objective: Self-medication is a common practice and an important health issue worldwide. The aim of this study was to determine the percentage of self-medication practice, patterns of use, self-medication attitudes, and to explore the occurrence of side effects resulting from self-medication practice among the adult population in Selangor, Malaysia.

Methods: This cross-sectional survey used a validated questionnaire administered to adults $18 \mathrm{y}$ and above residing in Selangor.

Results: A total of 401 completed questionnaires were analyzed. The majorities of the participants were Malay (91.5\%) and went to college or university (89.3\%). One-third self-medicated in the past two weeks prior to the survey. Self-medication was significantly associated with age $(\mathrm{p}=0.009)$ and race $(\mathrm{p}=0.038)$. Among the respondents, $83.8 \%$ would search for information before practicing self-medication. Modern healthcare professionals (58.4\%) and the internet (47.1\%) were the most common source of information about drugs for self-medication. The main reason for self-medication was the illness perceived as minor (79.1\%). Two-thirds of the respondents $(66.6 \%)$ had a satisfactory attitude towards selfmedication practices.
\end{abstract}

Conclusion: The public needs to be better informed on responsible self-medication to ensure safe, effective, and rational use of medicines.

Keywords: Adult, Attitude, Pattern, Self-Medication, Questionnaire, Malaysia

(c) 2017 The Authors. Published by Innovare Academic Sciences Pvt Ltd. This is an open access article under the CC BY license (http://creativecommons.org/licenses/by/4.0/) DOI: http://dx.doi.org/10.22159/ijpps.2017v9i5.16445

\section{INTRODUCTION}

Self-care is an approach taken by individuals to establish and maintain health as well as to prevent, and treat illness. Selfmedication is a part of self-care and can be defined as the selection and use of medicines by individuals to treat self-recognized illnesses or symptoms [1]. It comprises of intermittent or continued use of prescribed medications for some chronic or recurring illnesses [1], shared use of medications with other family members [2], or the use of leftover medicines stored at home [3].

Many studies have been conducted on self-medication worldwide [2,4-9]. The factors influencing self-medication reported include low perceived the seriousness of the disease, high costs of visiting a doctor, lack of time to visit a doctor, and easy access $[4,8]$. This practice is linked to many possible benefits [10] and risks [10-12].

Although it helps reduce the load on the medical services, it is not risk-free. Inappropriate use of drugs during self-medication may result in a financial burden to both the government and consumer, due to possible adverse effects and drug-drug or alcohol-drug interactions [10].

Knowledge concerning the patterns of self-medication and factors influencing this practice is essential. It helps identify the magnitude of this issue, prior to any intervention for promoting a safe, effective, and rational use of drugs in self-medication. In Malaysia, selfmedication is also a common practice [13].

However, no published study conducted locally found reported on the occurrence of side effects resulted from self-medication.

Given this, the present study was conducted to determine the percentage of self-medication practice, patterns of use, selfmedication attitudes and to explore the occurrence of side effects due to self-medication practice, among the adult population in Selangor, Malaysia.

\section{MATERIALS AND METHODS}

A cross-sectional study using a validated questionnaire was carried out among the adult population in Selangor, one of the states in Malaysia. Selangor is the largest state in Malaysia by population, with an estimated population of 6.14 million and size of 7,964 $\mathrm{km}^{2}[14]$. A convenience sampling method was adopted and data were collected from September to October 2014. This study employed two methods of data collection: web-based and paper based. For web-based data collection, a questionnaire was created using Google Docs and a web-link was circulated among researcher's contacts by e-mail, online social networking service, and mobile messaging application. For paper-based data collection, the researcher distributed the questionnaires to students at Universiti Teknologi Majlis Amanah Rakyat (MARA), Puncak Alam Campus and staff at pharmacy headquarters, with prior permission from the respective institution and office. The questionnaire was also circulated to adults who visited a selected private community pharmacy in Selangor. The return of the completed questionnaire was considered to imply informed consent. OpenEpi online sample size calculator was used for sample size calculation [15]. The required sample size calculated based on 33\% prevalence, 95\% confidence interval, and 5\% margin of error. Adults $18 \mathrm{y}$ old and above who were able to read and understand either English or Malay language were included in this study. The exclusion criterion was those residing outside Selangor. At the end of this study, 401 respondents were included in the final analysis.

The initial version of the questionnaire was developed in the English language by the research team through extensive literature review [2,5,7,16-18]. A 29-item structured questionnaire, comprising of three sections, was used for data collection. The first part consisted of 10 items related to socio-demographics including age, gender, marital status, ethnic group, highest education level, employment, monthly household income, health insurance, the area of residence, and whether the participant's occupation or participant's family's occupation were related to healthcare. The second part contained 10 
questions about self-medication practice, type and amount of medication used, sources of information, sources of medication, and occurrence of undesirable effects after practicing self-medication. The last part consisted of nine statements to evaluate the attitude of the adult population towards self-medication. Within this domain, a five-point Likert scale format (strongly agree/agree/neutral/ disagree/strongly disagree) was used to assess the responses. For positive attitude statements, scores of “ 5 ", “4", “3", " 2 ", and " 1 " for "strongly agree", "agree", "neutral", "disagree", and "strongly disagree", were allocated respectively. The above scoring system was reversed for negative attitude statements. The scores were then transformed into percentage scores by dividing the scores obtained with the maximum possible scores, then multiplied by $100 \%$. Arbitrary cut-off points of $70 \%$ were used, where scores above $70 \%$ were considered satisfactory, and scores $70 \%$ and below were considered unsatisfactory [19].

The questionnaire was translated to Malay language, checked and verified by the National Institute of Translation Malaysia [20]. The bilingual version of the questionnaire was then tested for validity and reliability. A group of local pharmacy experts, consisting one academician and three practitioners, assessed the questionnaire for content validity. Major changes were made by reducing and revising the items according to comments and recommendations from the experts. An overall percentage of agreement between the experts was calculated to get a content validity index (CVI) for the entire questionnaire. The CVI was 0.92 and considered acceptable [21]. The questionnaire was then pre-tested with a cognitive debriefing on 25 adults, to determine the clarity of the terms used. Some words were amended based on comments and recommendations. Finally, the revised questionnaire was fielded among 100 adult population in Selangor, to assess its internal consistency. The resulting Cronbach's alpha coefficient was 0.661 and in the acceptable range [20].

The data were computed and analyzed using STATA version 12.0 (Stata Corp, College Station, Texas, USA). Descriptive statistics were used to describe socio-demographic characteristics of the respondents, the prevalence, and patterns of self-medication practice. Chi-square test was used to test the association between socio-demographic characteristics and practice of self-medication. A p-value of less than 0.05 was considered as statistically significant.

The Research Ethics Committee, Research Management Institute, Universiti Teknologi MARA, reviewed and approved the study protocol. The study was registered in the National Medical Research Registry (NMRR) with registration identification NMRR-14-109422727.

\section{RESULTS}

A total of 401 of the adult population were included in the final analysis. More than half $(53.6 \%)$ of the respondents were female and $39.9 \%$ of them were between the ages of 25 and 34 . The majority of the respondents were Malay $(91.5 \%)$, while half were single (51.1\%). As for the highest education level, $89.3 \%$ went to college/university. $29.9 \%$ worked in the public sector and $31.9 \%$ of the respondents came from families with a monthly household income of more than RM5000.

Of the total number of respondents, 9.5\% were suffering from a chronic disease or medical condition such as diabetes, hypertension, or heart disease. We found that $45.9 \%$ were taking vitamins, $30.7 \%$ were taking minerals or supplements, and $15.0 \%$ consumed herbs or traditional medicines. $41.6 \%$ were taking at least one to two medications daily, while almost half $(45.1 \%)$ did not take any daily medication (table 1).

The immediate reactions of respondents experiencing minor illnesses are presented in table 1 . Half $(54.6 \%)$ of the respondents had ever practiced self-medication when experiencing minor illnesses. However, respondents who had practiced self-medication for the past two weeks prior to this survey constituted one-third $(33.9 \%)$ of the sample (table 1). There was a significant association between self-medication with age group and race (table 2). Respondents aged 35-44 y old were found to practice selfmedication more than other age groups $(p=0.009)$. The results also indicated that non-Malays practice a significantly higher percentage of self-medication compared to Malays $(50.0 \%$ versus $32.4 \%)$ $(\mathrm{p}=0.038)$.

Table 1: Distribution of respondents based on data related to self-medication (N: 401)

\begin{tabular}{|c|c|c|}
\hline Data related to self-medication & Frequency & $\%$ \\
\hline \multicolumn{3}{|c|}{$\begin{array}{l}\text { 1. Are you currently taking any medication for chronic disease/any medical conditions (i.e. diabetes, hypertension or } \\
\text { heart disease)? }\end{array}$} \\
\hline Yes & 38 & 9.5 \\
\hline No & 363 & 90.5 \\
\hline \multicolumn{3}{|c|}{ 2. Are you currently taking the following preparations/medications: } \\
\hline (a) Vitamins & 184 & 45.9 \\
\hline (b) Minerals or supplements & 123 & 30.7 \\
\hline (c) Herbs or traditional medicines & 60 & 15.0 \\
\hline \multicolumn{3}{|c|}{ 3. How many types of medication do you take in a day? } \\
\hline (a) None & 181 & 45.1 \\
\hline (b) $1-2$ & 167 & 41.6 \\
\hline (c) 3-5 & 51 & 12.7 \\
\hline (d) 6-10 & 1 & 0.2 \\
\hline (e) $>10$ & 1 & 0.2 \\
\hline \multicolumn{3}{|c|}{$\begin{array}{l}\text { 4. If you are experiencing minor illnesses (i.e. cough/cold/allergy/fever/pain, etc.), what is the first action that you will } \\
\text { take? }\end{array}$} \\
\hline (a) No action taken & 49 & 12.2 \\
\hline (b) Self-medication & 219 & 54.6 \\
\hline (c) Consult doctor & 115 & 28.7 \\
\hline (d) Consult pharmacist & 18 & 4.5 \\
\hline \multicolumn{3}{|c|}{$\begin{array}{l}\text { 5. Have you taken any medication in the past TWO weeks by your own decision (without getting advice from healthcare } \\
\text { professionals)? }\end{array}$} \\
\hline Yes & 136 & 33.9 \\
\hline No & 265 & 66.1 \\
\hline
\end{tabular}

$\mathrm{N}=$ total number of respondents

Among the respondents, $83.8 \%$ would look for information about medications before practicing self-medication. The most common source of information for self-medication was modern healthcare professionals (58.4\%). Other sources of information reported by the respondents included medical related references such as Micromedex and Lexicomp, and published article/journal (1.0\%) (table 3). 
Table 2: Distribution of respondents according to patterns of self-medication practice $(\mathrm{N}=401)$

\begin{tabular}{|c|c|c|}
\hline Patterns of self-medication & Frequency & $\%^{a}$ \\
\hline \multicolumn{3}{|l|}{ 6. If you have any concern about medication, do you look for } \\
\hline \multicolumn{3}{|l|}{ Information about that medication before practicing self-medication? } \\
\hline Yes & 336 & 83.8 \\
\hline No & 40 & 10.0 \\
\hline \multicolumn{3}{|l|}{ 6. (a) If yes, where do you get the information? } \\
\hline Modern healthcare professional & 234 & 58.4 \\
\hline Traditional and complementary practitioners & 13 & 3.2 \\
\hline Common information and entertainment channel (TV, radio etc.) & 36 & 9.0 \\
\hline Printed materials (magazines, newspaper) & 53 & 13.2 \\
\hline Patient Information Leaflets & 95 & 23.7 \\
\hline Internet & 189 & 47.1 \\
\hline Friends, family or neighbors & 104 & 25.9 \\
\hline Others & 4 & 1.0 \\
\hline \multicolumn{3}{|l|}{ 7. Where do you usually obtain the medication to practice self-medication? } \\
\hline Hospital & 91 & 22.7 \\
\hline Clinic & 215 & 53.6 \\
\hline Pharmacy Outlet & 286 & 71.3 \\
\hline Grocery shop & 65 & 16.2 \\
\hline Leftover medication & 95 & 23.7 \\
\hline Direct sales & 14 & 3.5 \\
\hline Traditional medicine outlet & 13 & 3.2 \\
\hline Friends, family or neighbors & 67 & 16.7 \\
\hline \multicolumn{3}{|l|}{ 8. Why do you choose to practice self-medication? } \\
\hline Medication given by the doctor was not effective & 19 & 4.7 \\
\hline Mildness of illness & 317 & 79.1 \\
\hline Prior experience or knowledge about disease and treatment & 187 & 46.6 \\
\hline Personal convenience & 104 & 25.9 \\
\hline Suggestion of family, friend or neighbor & 61 & 15.2 \\
\hline In emergency use & 74 & 18.5 \\
\hline Embarrass of discussing own condition & 5 & 1.2 \\
\hline Less costly & 52 & 13.0 \\
\hline Avoiding long waiting time to get medical treatment & 90 & 22.4 \\
\hline Others & 3 & 0.7 \\
\hline \multicolumn{3}{|l|}{ 9. Which type of medication you normally used when practicing } \\
\hline \multicolumn{3}{|l|}{ Self-medication? } \\
\hline Pill for headache (i.e. Paracetamol/Panadol) & 310 & 77.3 \\
\hline Cough or flu medicines & 265 & 66.1 \\
\hline Vitamins or minerals or supplements & 152 & 37.9 \\
\hline Painkiller (i.e. Aspirin, ibuprofen) & 316 & 78.8 \\
\hline Medication for gastric or heartburn or antacids (i.e. Actal) & 80 & 20.0 \\
\hline Herbs or traditional medicines & 58 & 14.5 \\
\hline Medicated skin products (i.e. Agnesia $($ ) & 66 & 16.5 \\
\hline Antibiotics & 36 & 9.0 \\
\hline Others & 1 & 0.2 \\
\hline \multicolumn{3}{|c|}{ 10. Have you ever experienced any undesirable effect after practicing self-medication? } \\
\hline Yes & 22 & 5.5 \\
\hline No & 365 & 91.0 \\
\hline
\end{tabular}

Table 3 also shows the distribution of respondents based on sources of drugs used, reasons for practicing self-medication and type of drugs commonly used during self-medication. More than half of the respondents reported pharmacy outlet $(71.3 \%)$ or clinic $(53.6 \%)$ as their sources of drugs, while $23.7 \%$ of the respondents used leftover medication when self-medicating.

The most common reasons for practicing self-medication reported by the respondents were that they perceived their illness as a minor one $(79.1 \%)$ and previous experience or knowledge about the disease and treatment (46.6\%). Painkillers $(78.8 \%)$ and pills for headache $(77.3 \%)$ were the most common drugs self-medicated by the participants. It was also observed that $9.0 \%$ of the participants reported having self-medicated themselves with Antibiotics.

When asked about attitudes toward self-medication practice, the majority (92.2\%) agreed that it was important to inform the doctor/pharmacist about other medications/supplements that they are taking, upon consultation with them. A few $(9.5 \%)$ respondents were scared to consult a doctor if their illness persisted after practicing self-medication. Most of the respondents (91.3\%) agreed that reading the medication label is not a waste of time and the majority (94.5\%) felt it was important to check the expiry date of the medications during the purchase or before consumption. Almost all of the respondents (94.5\%) agreed that they would take medications, according to the instructions on the label or as directed by a healthcare practitioner.

Only $7.4 \%$ agreed that they would practice self-medication irrespective of the seriousness of the illness. Most of the respondents $(70.8 \%)$ agreed that they would keep leftover medications at home for future use and $66.6 \%$ agreed that they would recommend the medicine they took to family, friends, or neighbors. Half of the respondents (53.1\%) agreed that they would share their medications, with a family member or a friend who was sick (table 4). More than half of the respondents (66.6\%) had a satisfactory level of attitude towards self-medication practices with total scores of over $70 \%$, while the remaining respondents $(33.4 \%)$ had an unsatisfactory level of attitude with total scores of $70 \%$ and below. 
Table 3: Socio-demographic characteristics of respondents according to practice of self-medication for the past two weeks (N: 401)

\begin{tabular}{|c|c|c|c|c|c|c|}
\hline \multirow[t]{2}{*}{ Socio-demographic characteristics } & \multicolumn{4}{|c|}{ Use of self-medication } & \multirow[t]{2}{*}{$\mathbf{x}^{2}$} & \multirow[t]{2}{*}{ p-value* } \\
\hline & $\begin{array}{l}\text { Yes (n: 136) } \\
\text { frequency }\end{array}$ & $\%$ & $\begin{array}{l}\text { No (n: 265) } \\
\text { frequency }\end{array}$ & $\%$ & & \\
\hline \multicolumn{7}{|l|}{ 1. Age group } \\
\hline 45 and above & 12 & 27.9 & 31 & 72.1 & 11.511 & 0.009 \\
\hline $35-44$ & 26 & 52.0 & 24 & 48.0 & & \\
\hline $25-34$ & 58 & 36.3 & 102 & 63.7 & & \\
\hline $18-24$ & 40 & 27.0 & 108 & 73.0 & & \\
\hline \multicolumn{7}{|l|}{ 2. Gender } \\
\hline Female & 69 & 32.1 & 146 & 67.9 & 0.687 & 0.407 \\
\hline Male & 67 & 36.0 & 119 & 64.0 & & \\
\hline \multicolumn{7}{|l|}{ 3. Marital status } \\
\hline Single & 63 & 30.7 & 142 & 69.3 & 1.897 & 0.168 \\
\hline Married & 73 & 37.2 & 123 & 62.8 & & \\
\hline \multicolumn{7}{|l|}{ 4. Number of children (if any) } \\
\hline None & 11 & 32.4 & 23 & 67.6 & 1.518 & 0.824 \\
\hline 1 & 19 & 39.6 & 29 & 60.4 & & \\
\hline 2 & 21 & 35.6 & 38 & 64.4 & & \\
\hline 3 & 8 & 33.3 & 16 & 66.7 & & \\
\hline More than 3 & 14 & 45.2 & 17 & 54.8 & & \\
\hline \multicolumn{7}{|l|}{ 5. Ethnic group } \\
\hline Malay & 119 & 32.4 & 248 & 67.6 & 4.288 & 0.038 \\
\hline Non-Malay & 17 & 50.0 & 17 & 50.0 & & \\
\hline \multicolumn{7}{|l|}{ 6. Highest education level } \\
\hline College/University & 123 & 34.4 & 235 & 65.6 & 0.291 & 0.589 \\
\hline Lower than College/University & 13 & 30.2 & 30 & 69.8 & & \\
\hline \multicolumn{7}{|l|}{ 7. Occupation } \\
\hline Public sector & 41 & 34.2 & 79 & 65.8 & 10.568 & 0.061 \\
\hline Private sector & 42 & 38.5 & 67 & 61.5 & & \\
\hline Self-employed & 11 & 57.9 & 8 & 42.1 & & \\
\hline Housewife & 0 & 0.0 & 3 & 100.0 & & \\
\hline Retired/Unemployed & 10 & 22.7 & 34 & 77.3 & & \\
\hline Student & 32 & 30.2 & 74 & 69.8 & & \\
\hline \multicolumn{7}{|l|}{ 8. Monthly household income } \\
\hline More than RM 5000 & 49 & 38.3 & 79 & 61.7 & 9.799 & 0.081 \\
\hline RM 4001-RM 5000 & 17 & 37.8 & 28 & 62.2 & & \\
\hline RM 3001-RM 4000 & 15 & 34.1 & 29 & 65.9 & & \\
\hline RM 2001-RM 3000 & 19 & 47.5 & 21 & 52.5 & & \\
\hline RM 1001-RM 2000 & 9 & 25.7 & 26 & 75.3 & & \\
\hline RM 1000 and below & 27 & 24.8 & 82 & 75.2 & & \\
\hline \multicolumn{7}{|l|}{ 9. Do you have any health insurance? } \\
\hline Yes & 82 & 35.7 & 148 & 64.3 & 0.726 & 0.394 \\
\hline No & 54 & 31.6 & 117 & 68.4 & & \\
\hline \multicolumn{7}{|l|}{$\begin{array}{l}\text { 10. Is your occupation or your family's } \\
\text { occupation related to healthcare? }\end{array}$} \\
\hline Yes & 52 & 35.6 & 94 & 64.4 & 0.296 & 0.586 \\
\hline No & 84 & 32.9 & 171 & 67.1 & & \\
\hline
\end{tabular}

$\mathrm{N}=$ total number of respondents; $\mathrm{n}=$ number of responses received; *p-value $<0.05=$ statistically significant.

Table 4: Distribution of respondents according to attitude towards self-medication practice (N: 401)

\begin{tabular}{|c|c|c|c|c|c|c|}
\hline \multirow[t]{2}{*}{ Item } & \multirow[t]{2}{*}{ Statement } & \multicolumn{5}{|c|}{ Responses (\%) } \\
\hline & & SA & $\mathbf{A}$ & $\mathbf{N}$ & D & SD \\
\hline 1 & $\begin{array}{l}\text { It is important to inform the doctor/pharmacist about the other medication/supplement that I took } \\
\text { upon consultation with them. }\end{array}$ & 50.6 & 41.6 & 7.0 & 0.2 & 0.5 \\
\hline 2 & I am afraid to consult a doctor if my illnesses persist after I self-medicate** & 1.5 & 8.0 & 12.0 & 49.1 & 29.4 \\
\hline 3 & Reading the medication label is a waste of time.* & 1.0 & 2.7 & 5.0 & 37.4 & 53.9 \\
\hline 4 & It is important to check the expiry date on the medication during purchasing or before taking it. & 67.8 & 26.7 & 2.0 & 1.0 & 2.5 \\
\hline 5 & $\begin{array}{l}\text { I will take medications, according to the instructions on the label, or as directed by a healthcare } \\
\text { practitioner. }\end{array}$ & 59.6 & 34.9 & 5.0 & 0.2 & 0.2 \\
\hline 6 & I will practice self-medication irrespective of the seriousness of the illness.* & 2.2 & 5.2 & 15.0 & 49.1 & 28.4 \\
\hline 7 & I normally will keep leftover medications at home for future use. & 20.9 & 49.9 & 19.5 & 6.7 & 3.0 \\
\hline 8 & If someone in my family/friend is sick, I will share my medications with them. & 11.5 & 41.6 & 23.9 & 16.5 & 6.5 \\
\hline 9 & $\begin{array}{l}\text { I will recommend to my family/friends/neighbors the medicine I took if they experience the same } \\
\text { illness as me.* }\end{array}$ & 13.7 & 52.9 & 22.2 & 9.7 & 1.5 \\
\hline
\end{tabular}

$\mathrm{N}=$ total number of respondents, $\mathrm{SA}=$ Strongly Agree; $\mathrm{A}=$ Agree; $\mathrm{N}=$ Neutral; $\mathrm{D}=$ Disagree; $\mathrm{SD}=$ Strongly Disagree; *=negative statement. 


\section{DISCUSSION}

The current finding that almost one-third of the study population had self-medicated is close to a national study conducted in Malaysia [13]. In other studies conducted previously within Malaysia, the percentage of self-medication was shown to be ranging between $62.7 \%$ and $80.9 \%$ [2,23-25]. In studies conducted in other developing countries, the percentage of self-medication was shown to be $32.0 \%$ in China [4], 39.0\% in Ethiopia [18], 39.5\% in Jordan [6], and $55.0 \%$ in Egypt [26].

Possible reasons for the differences in the percentage may be due to differences in socio-demographic and socio-economic status, apart from different methodologies used by the researchers.

The data from the present study showed that there was a significant association between self-medication with age group and race. Our findings are similar to a study conducted in Saudi Arabia [5], where young individuals were more likely to practice self-medication compared to older ones. In contrast, a previous study conducted in Malaysia reported no significant association between selfmedication practices with age and gender [13]. The current finding that those who were young were more likely to self-medicate suggests that healthcare professionals should be actively involved in public education campaigns and focused more on the youngsters during the campaigns. However, the findings may not be appropriate to generalize to the whole population due to sampling bias, as the majority of the respondents (91.5\%) were Malay.

Out of 401 respondents, $5.5 \%$ of them reported that they had experienced undesirable effects after practicing self-medication. This finding was comparable with another study conducted in India [27]. This issue warrants the role of pharmacists in providing adequate information on drugs for self-medication, including information regarding possible side effects that they might experience by consuming the drugs.

The two major reasons for self-medication reported by other studies were the simplicity of the illness $[16,27,28]$ and adequate knowledge or previous experience $[16,29]$. Similar observations were reported in our study in which respondents reported that the reasons for practicing self-medication were their perception that the illness is minor $(79.1 \%)$ and previous experience or knowledge about the disease and treatment (46.6\%). These situations might expose the respondents to potential danger, as they are exposed to the risk of misdiagnosis and thus not getting the right treatment [17]. Conversely, an implication of this practice is possible prevention and treatment of symptoms that do not need medical attention and thus reducing the burden on medical services [10].

The results of many studies have pointed out that the two most commonly used drugs in self-medication were analgesics and cough or flu medicines $[2,7,16-18,23,24,28,30]$. Our study showed similar findings and correlated well with the fact that a headache, fever, and cough/cold/sore throat were among the most common illnesses leading to self-medication $[18,31,32]$. However, selfmedication with analgesics can cause serious health problems if they are not used appropriately. High doses of paracetamol can cause liver damage, while overuse of analgesics such as non-steroidal antiinflammatory drugs (NSAIDs) may lead to drug-induced gastrointestinal toxicity [33].

The present findings revealed that the main source of obtaining medications used when self-medicated was pharmacy outlets. This may due to the large numbers of retail pharmacies in Selangor, and thus easily accessible over-the-counter medications for the public [34]. These findings were in accordance with other studies conducted in Malaysia [2, 7, 23], India [29], Pakistan [31], and United Arab Emirates [35].

This study found that more than half of the respondents took at least one type of medications daily, which include other medications for chronic conditions, vitamins, minerals, supplements, herbs or traditional medicines. It is very important to consult a doctor or pharmacist before consuming any new medications to avoid the occurrence of any drug interactions. When two drugs are taken together, the overall effect of one or both of the drugs may be bigger or smaller than desired, which may cause an overdose or underdose, respectively. An overdose may increase the risk of side effects to occur. On the other hand, underdose may reduce the therapeutic effect of a drug or even worse, impotent to provide any healing effects at all [36].

The majority of the respondents disagreed that they felt scared to consult a doctor if their illness persisted after practicing selfmedication. A similar result was also reported previously [37]. It is essential to consult a doctor when the patient has suffered minor illness for a long time without treatment or the illness is not relieved with treatment. Although it is uncommon, minor illnesses such as headache may be a sign of a serious medical condition.

In our study, the majority (94.5\%) of the respondents agreed that they will take medications, according to the instructions on the label or as directed by a healthcare practitioner. However, other study reported otherwise, where $43.3 \%$ respondents reported that they adjusted the dosage of the drug prescribed to them based on the course of their symptoms $[25,31]$. This is a dangerous act as it could cause severe or fatal adverse effects as an effect of overdosing or under dosing [38].

The negative behaviour of keeping leftover medications at home for future use was reported by $70.8 \%$ of the respondents. Our findings on this aspect were similar to other studies where $4.0 \%$ [38] and $22.5 \%$ [25] respondents reported that they kept their unused or leftover medications. The possible reasons may be that it takes the effort to dispose of the medications properly and they may think it is important to keep something that may be useful later on. In return, they do not have to go through the hassle of buying it in the future. However, any unused or leftover medications should not be kept at home for future use, as they should be returned to the pharmacy for proper disposal [39].

The strengths of the present study include the fact that it reported the percentage of respondents who ever experienced adverse effects resulting from self-medication practice. About one-tenth of respondents had experienced it. In addition, two-thirds of the study population had a satisfactory attitude towards self-medication practices, similar to findings elsewhere, with positive attitudes towards self-medication $[26,40]$. However, no summation of scoring was mentioned in the other published literature measuring selfmedication attitude. The present study reported summation of the total score for items under attitude domain and further categorized into satisfactory, and unsatisfactory. The arbitrary cut-off points were used to categorise the level of the attitude to satisfactory and unsatisfactory.

We acknowledge that the present study had a few limitations. As this was a self-administered survey, the accuracy of the results was heavily dependent upon information given by respondents and open to recall bias. Apart from this, selection bias may occur due to convenience sampling as we only distributed the paper-based questionnaire to three facilities; university, office, and community pharmacy. The findings may not be appropriate to generalize to the whole population. Studies cover more facilities need to be carried out among the adult population at large to understand the percentage and patterns of self-medication practice in Selangor. However, we distributed the web-based questionnaire to get a more comprehensive picture of self-medication among the adult population in Selangor. A further limitation is that only those who were internet-savvy and in the circle of contacts of respondents' contacts were likely to participate in this study. Another limitation was that informed consent from participants was not explicitly taken during data collection. Lastly, this study assumed all items carry the same weight for all the items which measure the level of attitude. However, certain item carries more weight compared to others. The type of side effects resulted from self-medication can also be explored in future studies.

\section{CONCLUSION}

The percentage of self-medication practices among the adult of the study population is comparable to studies conducted in other developing countries such as China, Ethiopia, and Jordan. Young 
individuals and non-Malays were found to be associated with selfmedication significantly. Although the rates of adverse effects experienced with self-medication are considered low, this is of great concern.

The young should be educated and made aware of the implications of self-medication. As retail pharmacies are the main source of medications, the community pharmacist plays a key role in educating the patients by providing necessary information on the medications and its rational use. Therefore, patients will be well equipped with knowledge before making an informed choice to practice self-medication. Efforts to increase awareness of the implications of self-medication could hopefully reduce the occurrence of irrational drug use and support the maintenance of health of individuals in society.

\section{ACKNOWLEDGEMENT}

We thank the Director-General of Health for his permission to publish this report. This study is a component of the first's author Master thesis in the Faculty of Pharmacy, Universiti Teknologi MARA, Puncak Alam Campus, Malaysia supervised by Prof. Noorizan Abd. Aziz. The authors would like to thank Prof. Dr. Yahaya Hassan, Nang Fay Chin, Norharlina Sulaiman and Robin Tan Tiow Heng (content validation of the questionnaire); Khairil Anuar Md. Isa (statistics); colleagues Faculty of Pharmacy, Universiti Teknologi MARA, Puncak Alam Campus, Malaysia; Juanita Halili (English), institution, office, and private community pharmacy for allowing us to conduct the survey; and respondents who completed the questionnaire.

\section{AUTHOR CONTRIBUTION}

SJ and NAA planned the study, were involved in study design, developed the study method and protocol, and critically revised the manuscript. SJ collected the data and conducted the analysis. All authors read and approved the final manuscript.

\section{CONFLICTS OF INTERESTS}

All authors have none to declare

\section{REFERENCES}

1. World Health Organization. The role of the pharmacist in selfcare and self-medication. Report of the 4th WHO Consultative Group on the Role of the Pharmacist. The Hague, The Netherlands; 1998.

2. Hassali MA, Shafie AA, Al-Qazaz H, Tambyappa J, Palaian S, Hariraj V. Self-medication practices among adult population attending community pharmacies in Malaysia: an exploratory study. Int J Clin Pharm 2011;33:794-9.

3. Loyola Filho AI, Lima-Costa MF, Uchôa E. Bambuí Project: a qualitative approach to self-medication. Cad Saude Publica 2004;20:1661-9.

4. Shaghaghi A, Asadi M, Allahverdipour H. Predictors of selfmedication behavior: a systematic review. Iran J Publ Heal 2014;43:136-46.

5. Alghanim SA. Self-medication practice among patients in a public health care system. East Mediterr Heal J 2011;17:409-16.

6. Al-Azzam SI, Al-Husein BA, Alzoubi F, Masadeh MM, Al-Horani MAS. Self-medication with antibiotics in jordanian population. Int J Occup Med Environ Health 2007;20:373-80.

7. Mohamed Azhar MI, Gunasekaran K, Kadirvelu A, Sunil G, Sadasivan S, Bhartu Madanial K. Self-medication: awareness and attitude among Malaysian urban population. Int J Collab Res Intern Med Public Heal 2013;5:436-43.

8. Responsible Self-Care and Self-Medication: A Worldwide Review of Consumer Surveys; 2014. Available from: http://www.wsmi.org/pdf/wsmibro3.pdf. [Last accessed on 01 Nov 2016]

9. Mythri H. Research on self-medication: a hype or a hope? A literature review. Asian J Pharm Clin Res 2016;9:28-31.

10. General Policy Issues: The benefits and risks of self-medication. WHO Drug Inf 2000;14:1-2.

11. Bernama. Health D-G: Don't practice self-medication blindly [Internet]. BorneoPost Online. Kuala Lumpur; 2014. Available from: http://www. theborneopost.com/2014/08/02/health-d- g-dont-practise-self-medication-blindly/. [Last accessed on 02 Aug 2014]

12. Kiyingi KS, Lauwo JAK. Drugs in the home: danger and waste. World Health Forum 1993;14:381-4.

13. Health seeking behavior. In: National Health and Morbidity Survey 2006 (NHMS III). Kuala Lumpur: Institute for Public Health and Institute for Health Systems Research; 2012. p. 69-72.

14. Selangor. Department of Statistics Malaysia. Available from: https://www.statistics.gov.my/index.php?r=column/coneandmen u_id=eGUyTm9RcEVZSIlmYW45dmpnZHh4dz09. [Last accessed on 21 Dec 2015]

15. Open Source Epidemiologic Statistics for Public Health. Available from: http://www.openepi.com/v37/SampleSize/ SSPropor.htm. [Last accessed on 21 Dec 2015]

16. Gutema GB, Gadisa DA, Kidanemariam ZA, Berhe DF, Berhe AH, Hadera MG, et al. Self-medication practices among health sciences students: the case of Mekelle University. J Appl Pharm Sci 2011;1:183-9.

17. Angamo MT, Wabe NT. Knowledge, attitude and practice of self medication in south-west ethiopia. Int J Pharm Sci Res 2012;3:1005-10.

18. Suleman S, Ketsela A, Mekonnen Z. Assessment of selfmedication practices in Assendabo town, Jimma zone, southwestern Ethiopia. Res Soc Adm Pharm 2009;5:76-81.

19. Agarwal R, Mohammad Daher A, Mohd Ismail N. Knowledge, practices and attitudes towards adverse drug reaction reporting by private practitioners from Klang Valley in Malaysia. Malaysian J Med Sci 2013;20:52-61.

20. Zalma AR, Safiah MY, Ajau D, Khairil Anuar MI. Reliability and validity of television food advertising questionnaire in Malaysia. Health Promot Int; 2013;1-8. Available from: http://www.ncbi.nlm.nih.gov/pubmed/24150531. [Last accessed on 25 Aug 2014]

21. Di Lorio CK. Measurement in Health Behaviour. 1st ed. San Francisco: John Wiley and Sons; 2005.

22. StataCorp. Stata Statistical Software: Release 12. College Station, TX: StataCorp LP.; 2011.

23. Chua SS, Sabki NH. Use of nonprescription medications by the general public in the Klang Valley. J Appl Pharm Sci 2011;1:93-8.

24. Ali AN, Tiong Kion Kai J, Keat CC, Dhanaraj SA. Self-medication practices among health care professionals in a Private University, Malaysia. Int Curr Pharm J 2012;1:302-10.

25. Ali SE, Ibrahim MIM, Palaian S. Medication storage and selfmedication behaviour amongst female students in Malaysia. Pharm Pract 2010;8:226-32.

26. El Ezz N, Ez-Elarab H. Knowledge, attitude and practice of medical students towards self-medication at Ain Shams University, Egypt. J Prev Med Hyg 2011;52:196-200.

27. Badiger S, Kundapur R, Jain A, Kumar A, Pattanshetty S, Thakolkaran N, et al. Self-medication patterns among medical students in South India. Australas Med J 2012;5:217-20.

28. Dutta S, Hazarika K. Pattern of self-medication and drugs use behavior among undergraduate students of medical and nonmedical colleges in a city of North-East Indian-a comparative study. Asian J Pharm Clin Res 2016;9:259-62.

29. Patel PM, Prajapati AK, Ganguly B, Gajjar BM. Study on impact of pharmacology teaching on knowledge, attitude and practice on self-medication among medical students. Int J Med Sci Public Heal 2013;2:181-6.

30. Kumar N, Kanchan T, Unnikrishnan B, Rekha T, Mithra P, Kulkarni V, et al. Perceptions and practices of self-medication among medical students in coastal South India. PLoS One 2013;8:1-5.

31. Zafar SN, Syed R, Waqar S, Zubairi AJ, Vaqar T, Shaikh M, et al. Self-medication amongst university students of Karachi: Prevalence, Knowledge, and Attitudes. J Pakistan Med Assoc 2008;58:214-7.

32. Mumtaz Y, Jahangeer SMA, Mujtaba T, Zafar S, Adnan S. Self medication among University Students of Karachi. J Liaquat Univ Med Heal Sci 2011;10:102-5.

33. Painkillers (analgesics). Derbyshire; 2011.

34. Health Ministry mulls incentives for opening community pharmacies. The Star Online. Petaling Jaya; 2013. 
35. Sharif SI, Sharif RS. Self-medication among non-healthcare students of the University of Sharjah, United Arab Emirates. Arch Pharm Pract 2014;5:35-41.

36. Ussai S, Petelin R, Giordano A, Malinconico M, Cirillo D, Pentimalli F. A pilot study on the impact of known drug-drug interactions in cancer patients. J Exp Clin Cancer Res 2015;34:1-6.

37. Gapor LE. The Effect of Health Education on the Knowledge and Attitude regarding Responsible Self-Medication on Common Illnesses, among Mothers of Barangay Sanjose, Aurora, Zamboanga, Del Sur; 2006

38. Kheir N, El Hajj MS, Wilbur K, Kaissi RML, Yousif A. An exploratory study on medications in Qatar homes. Drug Healthcre Patient Saf 2011;3:99-106.
39. Shah AP, Pamar SA, Ramkishan A, Mehta AA. Knowledge, attitude and practice (KAP) survey regarding the safe use of medicines in rural area of Gujarat. Adv Trop Med Public Heal Int 2011;1:66-70.

40. Kayalvizhi S, Senapathi R. Evaluation of the perception, attitude and practice of self-medication among business student in 3 select cities, South India. Int J Enterp Innov Manag Stud 2007;1:40-4.

\section{How to cite this article}

- Suhana Jawahir, Noorizan Abd Aziz. Self-medication among adult population in selangor, Malaysia. Int J Pharm Pharm Sci 2017;9(5):268-274 